\title{
Conceptual and Methodical Procedures of Psychomotor Learning
}

\author{
Jarmila Honzikova $^{1} \&$ Jan Janovec ${ }^{2}$ \\ ${ }^{1}$ University of West Bohemia, Plzen, Czech Republic \\ ${ }^{2}$ Jan Evangelista Purkyne University, Usti nad Labem, Czech Republic \\ Correspondence: Jarmila Honzikova, Faculty of Education, University of West Bohemia, Klatovska 51, Plzen \\ 30614, Czech Republic. Tel: 420-377-636-500. E-mail: jhonziko@kmt.zcu.cz
}

Received: August 12, 2012 Accepted: October 29, 2012 Online Published: December 12, 2012

doi:10.5539/cis.v6n1p15 URL: http://dx.doi.org/10.5539/cis.v6n1p15

\begin{abstract}
Author article stakes part in several projects focused just on development of technical creativity and imagination in students of faculties of education, teachers and primary school pupils. The article deals with the teacher's approach to the teaching of psychomotor skills, while specifically seeking to answer whether among teachers of technical education and practical activities, there are groups with significantly different approaches to teaching in terms of chosen objectives, methods and forms of teaching. This claim was first examined using a questionnaire survey focused on the objectives of education and further using Q-methodology concerning methods and forms. These examinations were performed as part of the "Nonverbal Creativity in Technical Education" project GACR 406/07/0109 and as part of the "The Development of School-age Pupils' Competencies in the Area of Psychomotor Skills" project by the Internal agency of the Faculty of Education at Jan Evangelista Purkyne University.
\end{abstract}

Keywords: psychomotor skills, educational objectives, teaching methods, forms of teaching, Q-methodology, teaching project, creative thinking

\section{Introduction}

Teaching psychomotor skills is one of the main tasks of technical education and practical activities subjects. There are two opposing opinions of psychomotor skills teaching processes. On the one hand, it is the process of simple imitation and multiple repetitions, on the other hand, a process during which the teacher leads pupils to think during learning, utilize their knowledge, check the progress and results of their work, analyze their mistakes and prevent them. This claim is universally accepted among the experts however its empiric study has yet been applied but marginally.

\section{Psychomotor Learning}

The process of psychomotor skills acquisition is divided into several phases, of which the first, cognitive phase is most important. The neglect of this phase leads to difficulties in further psychomotor skills acquisition. During this initial stage the pupil familiarises with the activity, process and execution. A very important moment here is a practical demonstration supplemented by verbal instructions. This phase is very difficult in terms of perception, imagination, memory, thinking and speech (Cap \& Mares, 2001).

The received information is used within the second phase, when the first attempts at the activity are carried out. Attention is paid to control and the pupil's self-control, working with errors and feedback.

During the last phase the pupil proceeds more independently. This phase takes the longest. Practical demonstration, verbal instruction, the exercise self-control and control, analysing errors and their removal - in other words feedback is still very important at this stage. Here the activities become automatic.

"During the acquisition of psychomotor skills and the performance of demanding psychomotor activities much depends on thought, knowledge, generally on all cognitive moments and processed experience" (Cap \& Mares, 2001). Psychomotor skills and abilities are also dependent on the motives and emotions, which are thereby affected. If the activity lacks motivational features, it becomes less effective and could lead to aversion toward further learning. Some changes in psychological and physiological processes occur during the acquisition of psychomotor skills. The movements and rhythm become standardized (e.g. hammer blows are initially unequally strong). Individual movements are combined in a whole (driving nails, knitting, crocheting), and gradually turn 
into a smooth operation. Thereby the movements become precise and time-efficient. Furthermore, one can observe improvements in perception and control, differentiation abilities, psychomotor coordination and in the coordination of internal organs with movements. No errors occur in individual requirements; the activities are carried out automatically and with minimal exhaustion.

Psychomotor skills can also be negatively affected and weakened in particular by the following factors: longer intervals in between the exercise, worsening of external conditions (light), negative changes to one's mental and physical state (exhaustion, illness), or external distracting stimuli that divert attention. However individual human differences also contribute in a substantially important way: nervous instability - stability, existing skills and experiences, health, intellect, temperament, motivation and one's emotional state (Honzikova, 2001).

From a methodological point of view, the correct process for the acquisition of psychomotor skills has already posed problems in the past. The traditional process was based on a practical demonstration, presentation and following imitation. On the one hand, the instruction and control of the pupils' task were so detailed that it restrained the pupils' independence, on the other hand the pupils were left with too much independence. For us it is important to combine both, however in a different scope and form considering individual people and skills. "Different psychomotor skills require different methodologies" (Cap \& Mares, 2001).

It is necessary to select the correct teaching process for practicing psychomotor skills:

- teaching by sections or as a whole - while practicing complex movement activities, it is better to proceed by sections. On the other hand, frequent repetition of individual elements could affect the pupil's motivation, and therefore it is more appropriate to choose teaching as a whole. It is good to separate the demanding elements of the activity and practice them separately using a combination of teaching as a whole and by sections.

- result quality, accuracy or speed - here a lot depends on the appropriate chosen method. In some cases it is better to practice at a slower pace in order to achieve high-quality results, prevent errors or remove them. Sometimes it is better to practice at a faster pace with well-allocated breaks, which are used for controlling, demonstration, analyzing the accuracy of the carried out activity and an overall evaluation.

During work education classes these methods are affected by the choice of the work outcome. If the teacher chooses an excessively complicated outcome, expecting the pupils to finish in a limited time it will lead to a rush and inaccurate work of the pupils.

When learning new psychomotor skills one uses a so-called transfer, which is a similar skill acquired in the past. Similar experiences, which the pupil acquired in previous activities may however also lead to errors, we call this interference. At this point it is very important to compare the previous and new activities for the pupils to realize what is different or similar about the new activity.

Psychomotor activities are an integral part of our lives and learning them is important for the education and development of our personality. The acquisition of psychomotor skills, such as work skills, is not only an isolated matter of mechanical drill, but it highly dependent on intellect and motivation.

Psychomotor skills and activities can be taught in two ways. One of these ways is a fierce process of imitation and constant repetition. The second process is where pupils are taught to think, analyze and predict their mistakes, to use their previously acquired knowledge and understanding, to not only check the results of their work, but also its development. This learning process is enabled through educational projects. Educational projects are integrated lessons, which present pupils with one or more tasks. The aim of the project is completing the task. To complete the task pupils need to find a great deal of information, they need to be able to process and use their existing knowledge, establish contacts with experts, know how to organize work, work as a team and learn to communicate. When completing the task students begin to recognize that school work has concrete useful forms. They learn that not only skills and knowledge play an important role in completing the task, but that the need of recognition and self-fulfilment are also very important, not forgetting the notion of meaningfulness. During the educational projects the pupils have an opportunity to meet some important needs such as the need for self-fulfilment, recognition and a sense of belonging. The projects also provide a sense of meaningfulness, which is an important motivating factor to the pupils.

As already noted, the acquisition process of psychomotor skills is divided into three phases, of which the first cognitive phase is most important. This phase cannot be neglected otherwise this could complicate the acquisition of additional psychomotor skills. At this stage the pupil familiarises with the activity, the process and the execution. A very important moment here is a practical demonstration supplemented by verbal instructions. In the following phase pupils use the received information and attempt the execution of the given activity. Here the teacher pays attention to the control, self-control and feedback from pupils. By the final stage, the pupils work independently and automatically. 


\section{General Education Programme}

Prepared by the Ministry of Education, Youth and Sport of the Czech Republic, the General Education Programme for Primary Education ("RVP ZV") has a character of a two-level curriculum document. In this sense of a curriculum, the document should formulate binding objectives (contents), provide for comprehensive conditions for meeting the set objectives, and create tools for objective evaluation of objective achievement levels. This General Education Programme defines the following:

- Primary education characteristics and general objectives (parts A and B of the document)

- Key competences, such as teaching competences; problem-solving competences; communicative competences; social and personal competences; civic competences; and working competences.

- Education contents expressed in nine education spheres and divided further into subjects. The education contents expressed in individual areas by means of "expected outputs" which rather describe the skills (competences) gained, and by means of the "subject matter".

- Education of pupils with special learning needs, material and other conditions for RVP ZV implementation, and principles for preparation of a school education programme (part $\mathrm{D}$ of the document).

It is indisputable that this document fails to satisfy especially the second and third parts of the requirements for curriculum, rather indicating the required solution only (www.vuppraha.cz).

Technical education is represented by the "Man and the World of Work" area, which is a subject simultaneously. I am not going to analyse here this whole area which has experienced many changes as against the "Primary School '96" education programme. The key competences which should be achieved by pupils at the end of primary education are an important connecting element for all the education areas. These six competences listed above correspond partially only with the EU-set key competences. Working competences create good opportunities for strengthening technical education at primary schools, and they should be developed in all subjects.

The RVP ZV is followed by the School Education Programme ("SVP ZV") as a second stage of the curriculum document. This document will be set up by schools themselves. An intensive work of teachers who will have to agree upon education priorities and strategies and on the methods of their fulfilment both in education and in the school life, is assumed. The Ministry of Education, Youth and Sport elaborated a manual for SVP preparation ("ZV Manual") to assist schools in designing their own programmes, create specimen structures, and address the most fundamental problems. The first knowledge shows that schools may experience greatest problems with the implementation of all key skills into all SVP subjects. A similar situation will occur in incorporation of cross-sectional topics into the SVP.

In addition to the education spheres and subjects, cross-sectional topics are very important in the RVP. These topics have a formative character in particular and contribute to achieving pupils' key skills. They can be implemented in school education programmes in the form of separate subjects, courses, projects or as extensions for education areas and subjects. RVP defines the following topics (each of which is concretized further in thematic spheres):

- Personality and social education

- Education of a democratic citizen

- Education to thinking in European and global contexts

- Multi-cultural education

- Environmental education (ecosystems, basic life preconditions, man-environment relation, ...)

Media education (critical reading, listening and observing media reports, construction of media reports, perception of media report authors, media functions and influence in society, creation of media reports, ...).

The last two topics open a vast space for extending the sphere of action of the education technical component at primary schools.

The Creative Technical Work which will be an output of the project mentioned above should help to implement the cross-sectional topics. This programme will be built upon research results and should show teachers and pupils the way as to how prepare and implement school teaching programmes in the sphere of technical education.

\section{Setting Educational Aims for Teaching Psychomotor Skills}

The teacher's choice of educational aims is important to identify the method of teaching psychomotor skills. The question raised in the questionnaire survey was as follows: Do teachers merely use imitation and manipulation as an educational aim in practical lessons and while teaching psychomotor skills, or do they also choose the development of creativity as an educational aim, i.e. do they develop the pupils' independent thinking by letting 


\section{them find their own solutions?}

This question was answered by the research study carried out at basic schools, where a sample of 70 respondents was chosen from among basic school primary level teachers. It is evident that these results cannot be generalized; however it can be assumed that they express a particular view of the issue. The mentioned results were the starting point and reason for the implementation of the research via Q-methodology presented below.

Manipulation as an aim of the psychomotor area is formed by teachers:

- always -8 respondents

- often -54 respondents

- sometimes -8 respondents

- rarely -0 respondents

- never -0 respondents

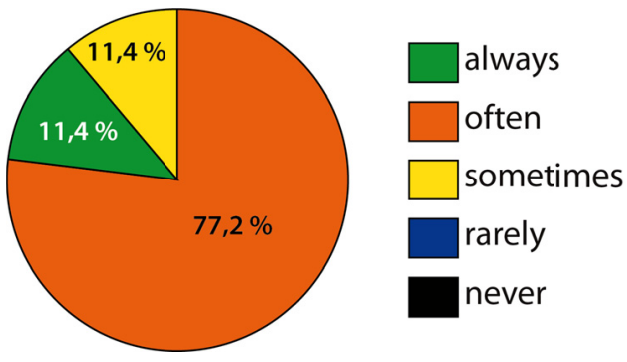

Figure 1. Manipulation as an aim

Imitation as an aim of the psychomotor area is formed by teachers:

- always -0 respondents

- often -30 respondents

- sometimes -40 respondents

- rarely -0 respondents

- never -0 respondents

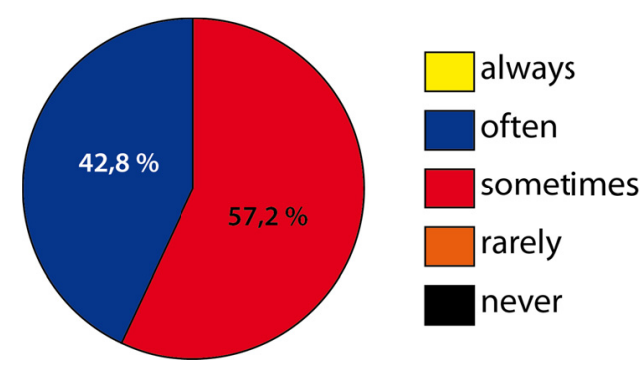

Figure 2. Imitation as an aim

Adaptation and creativity as an aim of the psychomotor area is formed by teachers:

- always -4 respondents

- often -8 respondents

- sometimes -48 respondents

- rarely - 10 respondents

- never -0 respondents

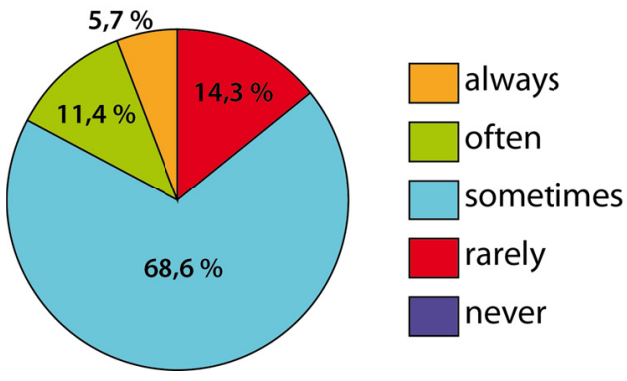

Figure 3. Adaptation and creativity as an aim

55 primary school teachers were asked about the attitudes of teachers toward forming educational aims, in this case, of adaptation and creativity. Teachers consider this aim - adaptation and creativity in the field of learning psychomotor skills:

- a fully inconvenient level of learning - 0 respondents,

- an inconvenient level of learning -4 respondents,

- an adequate level of learning - 15 respondents,

- a very good level of learning - 22 respondents,

- an excellent level of learning - 14 respondents.

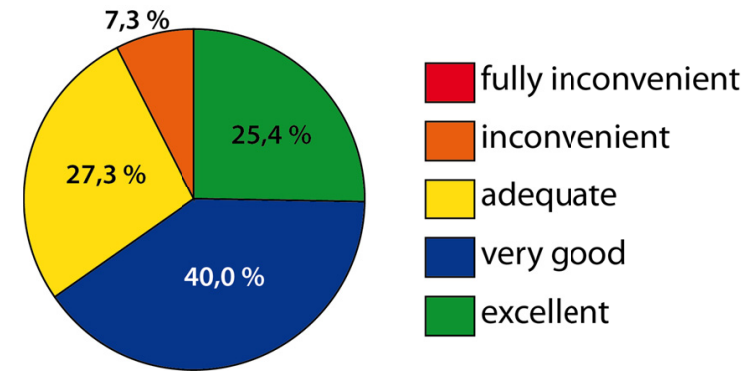

Figure 4. Adaptation and creativity as an aim 
The survey showed that in our schools the prevalent method of teaching psychomotor skills is still that of simulation, i.e. imitation and manipulation. Creativity as an aim of teaching psychomotor skills has also achieved a relatively high percentage. However, when we asked the teachers if they believed creativity a convenient level of learning psychomotor skills, the results became inconclusive. One must bear in mind that each lesson should provide pupils with enough space for creative work. Several conditions could be determined for such a lesson providing opportunities for the pupils' creative work, their support, appraisal of their ideas and thoughts, providing enough time to think about the problems, to construct ideas and to develop imagination.

\section{Methods and Forms of Psychomotor Skills Education}

The questionnaire survey method interpreted only via descriptive statistics does not provide valid and statistically substantiated results to confirm the initial assumption that there are two distinct groups among teachers with different approaches to teaching psychomotor skills. It has been decided that the next step would be to move away from the category of aims and pursue the methods and forms of education. It can be assumed that the teacher's choice of methods and forms is in fact much closer to the lessons in real practice. Further, due to the number of methods and forms, we assumed a more precise differentiation of the various groups of surveyed teachers and finally we expected a lesser result error due to the biased self-assessment of respondents' and their teaching.

Q-methodology was selected to determine the methods and forms of education. This method not only allows to determine the absolute values of the researched variables, but it is also an effective method for a statistical analysis, a search for similarities in the opinions of the surveyed sample of teachers, the respondents of the research.

\subsection{Survey Methodology}

Q-methodology has been successfully used in research, examining how a group of respondents evaluate a given set of objects, with there being a large number of these objects (Kerlinger, 1973). A total of 60 descriptive cards were used in the mentioned research for the area of educational forms and methods. The cards were marked with the letter "A" and with the relevant number of one of the sixty Q-types. These cards, using a short description in outline, reflected the characteristics of sixty different forms and methods of teaching manual skills. The Q-types were designed by the researchers and were practically tested during the pilot stage on a group of eight teachers. There was a need for a slight correction in two responses. During the survey the respondents were given the following question: "I prefer / don't prefer the following teaching forms and methods when teaching manual skills in the subject of work education". In accordance with the methodology of the research the respondents were required to divide the descriptive cards according to the significance of response into 11 groups from the most important to the least important. To enable and facilitate the processing of statistical results we chose the quasi-normal distribution according to the scheme 2-3-4-7-9-10-9-7-4-3-2, which approximates normal distribution. Respondents were therefore ordering individual Q-types into eleven groups according to the significance while having a pre-specified number of responses for each group according to the diagram. While processing the results a score on a scale from nil to ten points was attributed to the individual placement positions of Q-types from left to right.

Table 1. The most important forms and methods of teaching according to teachers

\begin{tabular}{cccl}
\hline Order & $\bar{a}$ & $\sigma$ & Q-type \\
\hline 1. & 7,29 & 2,19 & A33 motivational talk \\
2. & 7,00 & 2,51 & A14 demonstration of the practical activity by the teacher (i.e. working process) \\
3. & 6,98 & 2,38 & A21 motivational demonstration \\
4. & 6,95 & 2,05 & A31 motivational lecture \\
5. & 6,81 & 2,00 & A34 dialogue (communication of the teacher and pupils, pupils with each other) \\
6. & 6,55 & 2,12 & A32 conversation (communication of the teacher and pupils) \\
\hline
\end{tabular}

Another reason for using Q-methodology in research is the possibility to determine whether there are similarities between the assessments of descriptive cards by individual respondents and how great these similarities are. Pearson's correlation coefficient was used for the differential exact assessment of the relation tightness between 
the sorting of individuals. Correlation coefficients were calculated for all possible pairs of the surveyed people and the results were entered into a correlation matrix, which for its comprehensiveness is impossible to present.

More information about the types of sorting surveyed people can be introduced by the cluster analysis, whose purpose is to assign units of analysis, in our case individual teachers, to groups based on similarities (Chraska, 2007). Cluster analysis can obtain information for example, about whether there are certain types of people among the assessors who have submitted Q-type reviews featuring similar opinions. To identify such groups the method of k-diameters has been used in our research.

\subsection{Research Results}

42 primary level teachers from basic schools in the Usti nad Labem region have attended the survey. The time period during which surveyed teachers sorted cards into groups, was not limited during the administration of the method. Firstly, the indicators of the descriptive statistic were used and the arithmetic averages $\bar{a}$, of individual Q-types were calculated as was the standard deviation $\sigma$. The forms and methods of teaching regarded by teachers as most important in the process of teaching manual skills are listed in Table 1. In terms of the researched problem, the selection of conversational and motivational methods over methods directly associated with manual activities can be considered surprising, even though a relatively large standard deviation indicates a major variation of opinions on the importance of these Q-types.

To determine the specific types of teachers in terms of their view of the significance of methods and forms of manual skills teaching the correlation matrix was created (Table 2). The similarity of opinions was apparent between the two groups - groups of respondents with a relatively large value of the correlation coefficient. K-diameter method brought more accurate determination of these groups in terms of their representatives, where the larger group called the $\mathrm{X}$ has 19 respondents and in the less numerous group $\mathrm{Y}$ was found 12 respondents.

Table 2. Correlation matrix

\begin{tabular}{|c|c|c|c|c|c|c|c|c|c|c|c|c|c|}
\hline & $\mathrm{X} 1$ & $\mathrm{X} 2$ & $\mathrm{X} 3$ & $\mathrm{X} 4$ & $\mathrm{X} 5$ & $\mathrm{X} 6$ & $\mathrm{X} 7$ & $\mathrm{Y} 1$ & $\mathrm{Y} 2$ & $\mathrm{Y} 3$ & $\mathrm{Y} 4$ & $\mathrm{Y} 5$ & $\mathrm{Y} 6$ \\
\hline $\mathrm{X} 1$ & 1 & 0,54 & 0,56 & 0,56 & 0,56 & 0,4 & 0,28 & 0,2 & 0,21 & 0,15 & 0,11 & 0,05 & $-0,1$ \\
\hline $\mathrm{X} 2$ & 0,54 & 1 & 0,62 & 0,5 & 0,49 & 0,49 & 0,25 & 0,25 & 0,07 & -0 & 0,11 & 0,09 & -0 \\
\hline $\mathrm{X} 3$ & 0,56 & 0,62 & 1 & 0,37 & 0,42 & 0,34 & 0,37 & $-0,2$ & $-0,1$ & $-0,2$ & $-0,1$ & $-0,1$ & $-0,2$ \\
\hline $\mathrm{X} 4$ & 0,56 & 0,5 & 0,37 & 1 & 0,42 & 0,33 & 0,18 & 0,19 & 0,05 & -0 & $-0,1$ & 0,13 & 0,02 \\
\hline $\mathrm{X} 5$ & 0,56 & 0,49 & 0,42 & 0,42 & 1 & 0,33 & 0,42 & 0,2 & 0,19 & 0,1 & 0,14 & 0,21 & -0 \\
\hline $\mathrm{X} 6$ & 0,4 & 0,49 & 0,34 & 0,33 & 0,33 & 1 & 0,05 & 0,15 & 0,13 & 0,06 & 0,06 & -0 & -0 \\
\hline $\mathrm{X} 7$ & 0,28 & 0,25 & 0,37 & 0,18 & 0,42 & 0,05 & 1 & 0,03 & 0,2 & 0,04 & $-0,1$ & 0,15 & $-0,1$ \\
\hline $\mathrm{Y} 1$ & 0,2 & 0,25 & $-0,2$ & 0,19 & 0,2 & 0,15 & 0,03 & 1 & 0,33 & 0,27 & 0,24 & 0,23 & 0,1 \\
\hline $\mathrm{Y} 2$ & 0,21 & 0,07 & $-0,1$ & 0,05 & 0,19 & 0,13 & 0,2 & 0,33 & 1 & 0,75 & 0,65 & 0,47 & 0,22 \\
\hline $\mathrm{Y} 3$ & 0,15 & -0 & $-0,2$ & -0 & 0,1 & 0,06 & 0,04 & 0,27 & 0,75 & 1 & 0,71 & 0,46 & 0,15 \\
\hline $\mathrm{Y} 4$ & 0,11 & 0,11 & $-0,1$ & $-0,1$ & 0,14 & 0,06 & $-0,1$ & 0,24 & 0,65 & 0,71 & 1 & 0,43 & 0,21 \\
\hline $\mathrm{Y} 5$ & 0,05 & 0,09 & $-0,1$ & 0,13 & 0,21 & -0 & 0,15 & 0,23 & 0,47 & 0,46 & 0,43 & 1 & 0,35 \\
\hline Y6 & $-0,1$ & -0 & $-0,2$ & 0,02 & -0 & -0 & $-0,1$ & 0,1 & 0,22 & 0,15 & 0,21 & 0,35 & 1 \\
\hline
\end{tabular}

Both groups were evaluated by the arithmetic averages obtained for each Q-types and the corresponding standard deviation. The order and the values obtained for the first six Q-types in each group are presented in Tables 3 and 4. 
Table 3. Methods and forms of teaching seen as most important by the group X teachers

\begin{tabular}{cccl}
\hline Order & $\bar{a}_{X}$ & $\sigma$ & Q-type \\
\hline 1. & 8,68 & 1,45 & A21 motivational demonstration \\
2. & 8,63 & 1,09 & A14 demonstration of the practical activity by the teacher (i.e. working process) \\
3. & 7,74 & 2,27 & A33 motivational talk \\
4. & 7,47 & 1,96 & A31 motivational lecture \\
5. & 7,16 & 1,60 & A15 demonstration of finished products \\
6. & 7,11 & 1,65 & A30 narration (engaging telling of stories concerning the topic) \\
\hline
\end{tabular}

Table 4. Methods and forms of teaching seen as most important by the group $\mathrm{Y}$ teachers

\begin{tabular}{cccll}
\hline Order & $\bar{a}_{Y}$ & $\sigma$ & Q-type \\
\hline 1. & 7,83 & 1,99 & A35 discussion (conversation of teachers and students in order to defend the view) \\
2. & 7,58 & 1,75 & A33 motivational talk \\
3. & 7,08 & 1,98 & A56 group teaching \\
4. & 7,00 & 2,24 & $\begin{array}{l}\text { A9 project, students propose solutions and resolve sub-process steps without the help } \\
\text { of a teacher }\end{array}$ \\
5. & 6,92 & 1,66 & $\begin{array}{l}\text { A7 project, students propose a development of solution and partial steps are instructed } \\
\text { by teacher }\end{array}$ \\
6. & 6,92 & 1,61 & A34 dialogue (communication of the teacher and pupils, pupils with each other) \\
\hline
\end{tabular}

Although the precise definition of these two groups will require more investigation and the interpretation of the results will require more attention, some conclusions can be determined. Respondents of the X group prefer in the teaching of manual skills primarily the work practice according to the instruction given by teacher, these respondents consider the demonstration very important, not only the demonstration of practical activity but also of the final product. The emphasis is on pupil motivation by the teacher and in case of forms frontal teaching is preferred. Conversely, respondents of the $\mathrm{Y}$ group prefer project and problem methods of teaching, and some relatively new methods such as brainstorming, situational and simulation methods. Motivation is primarily based on conversation and in case of forms teaching in groups is preferred.

Quite a significant difference between the two studied groups of teachers is reflected in the opinions of project teaching. Table 5 shows the individual, to a certain degree theoretical possibilities of project teaching structure. Arithmetic averages were calculated, and also the difference between them, the value of the test standard criteria and statistical significance. To test the statistical significance of differences in averages of sector indicators the Student's t-test was used. In cases where normality of statistical files was not confirmed, the deciding on acceptance or rejection of the statistical significance of difference was based on the results of non-parametric test of Mann and Whitney. In terms of ranking, it is clear that the views of these two groups are almost contradictory. Very important and statistically confirmed differences are reflected in projects in which pupils propose an overall solution procedure. While the teachers of the $\mathrm{X}$ group arrange them to the second half of the preferred methods, the teachers of the $\mathrm{Y}$ group see them as preferred and they occupy top positions even in comparison with other methods. 
Table 5. The order of Q-types of groups $\mathrm{X}$ and $\mathrm{Y}$ in relation to the project teaching

\begin{tabular}{lcccccccc}
\hline Q-type & $\mathrm{X}_{\text {order }}$ & $\mathrm{Y}_{\text {order }}$ & $\bar{a}_{X}$ & $\bar{a}_{Y}$ & $\bar{a}_{X}-\bar{a}_{Y}$ & $t$ & $p$ \\
\hline $\begin{array}{l}\text { A9 project, students propose a development of } \\
\text { overall solution and resolve sub-steps without } \\
\text { the help of a teacher }\end{array}$ & 42. & 4. & 4,26 & 7,00 & $-2,74$ & 3,56 & $<0,01$ \\
$\begin{array}{l}\text { A8 project, students propose a development of } \\
\text { overall solution with the help of the teacher } \\
\text { solving the partial steps }\end{array}$ & 44. & 13. & 4,16 & 6,17 & $-2,01$ & 4,23 & $<0,01$ \\
$\begin{array}{l}\text { A7 project, students propose a development of } \\
\text { overall solution and sub-steps are instructed by } \\
\text { a teacher }\end{array}$ & 40. & 5. & 4,32 & 6,92 & $-2,60$ & 4,46 & $<0,01$ \\
$\begin{array}{l}\text { A6 project, teacher proposes a development of } \\
\text { overall solution and pupils solve sub-steps } \\
\text { (without instruction) }\end{array}$ & 50. & 39. & 3,74 & 4,58 & $-0,85$ & - & - \\
$\begin{array}{l}\text { A5 project, teacher proposes a development of } \\
\text { overall solution and pupils solve sub-steps } \\
\text { after the instruction }\end{array}$ & 21. & 34. & 5,58 & 4,75 & 0,83 & - & - \\
$\begin{array}{l}\text { A4 project, teacher proposes a development of } \\
\text { overall solution and also the individual } \\
\text { sub-steps }\end{array}$ & 28. & 53. & 5,16 & 3,17 & 1,99 & 2,22 & $<0,05$ \\
\hline
\end{tabular}

\section{Teaching Project}

Changes in work style in our schools occur with the change of our social environment. Teachers prepare their pupils for life in a society which we don't know exactly as to what demands on its members it will have and what abilities and skills it will require from them. It is clear, however, that the importance of creative thinking and practice in all spheres of human activities still increases.

Project-based method, almost forgotten in the past decades and widely discussed and used nowadays, is one of the many forms of alternative educational methods, which aim on pupils' practice. It is based on the belief that the message of education becomes significant only then, when it incorporates itself into human experience, and also on the assumption that one cannot separate cognition from activity. That is the creed of the contemporary school.

\subsection{Advantages and Implications of Project-Based Education}

An educational project stands for incorporated education, which confronts pupils with one or multiple tasks. The goal is fulfilling the task. Pupils are required to look up a set of information, to be able to use and process knowledge they already have, to get in touch with professionals, to be able to organize their work, to work as a team, to learn to communicate. While carrying out their tasks, pupils discover a practical form of schoolwork. They learn that not only abilities and knowledge play an important role in the task completion, but also the need to be respected, to self-fulfilment, and, the last but not the least, the awareness of the task's meaningfulness.

Valenta (1993) says, "The background of projects comprises the overall idea called concentration". Concentration as setting up common "cores", "basics", "situations" or "individual thoughts", around which the curriculum would be concentrated. That curriculum is ordinarily passed on in the form of individual separated subjects or thematic units inside those subjects. Hence concentration also means search for a new key or criterion, by which the curriculum could be arranged. Thus concentration of curriculum is a concentration of the subject matter around certain motive, core or a basic idea.

That concentration can:

- $\quad$ substitute (possibly for a certain amount of time) the existence of multiple subjects by joining certain parts of their matter around the core theme

- be used even within the scope of one subject, where it widens the structure of individual topics

- aim the curriculum of subjects - while preserving them - towards one central topic 
- be based - while preserving the subjects - on mere search of known inter-subject relations correlations

Sources of concentration cores can be

- the reality of life

- formulary subject matter

- connection of both

Concentration cores can have various forms:

- general topic - the core is usually formed by a notion, which presents itself as a generalization of a certain fact, which is generally significant to acquire

- actual object - the core is a certain unknown or a difficulty, which must be overcome for the didactic effect to appear

- educational goal - it becomes an actual core in those cases, where the pupil's personality change is the primary goal, and the message or theme etc. is only the secondary objective

While planning projects, it is important to observe certain principles, which arise from goals of our project. Kasikova attempted to define these principles (Kasikova, 1993):

- Attention towards child's needs and interests - almost every school, which states the needs and interests of a child as the basis of its effort, has a certain form of projects in its programme (e.g. Waldorf schools, or other alternative schools)

- Attention towards current situation - the principle of so called "opened school" goes here, meaning opening the knowledge for people. Motivation used in projects comes from the personal situation of an individual, from the school and wider social environment.

- Subject relations - instead of separated information and abilities, typical for subject-based education, projects offer undivided knowledge. Seemingly unrelated disciplines can be connected in projects.

- Self-regulated teaching - projects change the role of a teacher to the one of a consultant, because the guiding activities are transferred to the pupil himself/herself.

- Orientation towards a product - projects aim for real life as much as possible, where, too, work and activity bring about products, and thus confirm the meaning of learning. Therefore it is important to document the progress and results of projects, as well as to present those results.

- Group realization - social psychology confirms the importance of social education of an individual in a group, both during the development of his/her social abilities, and in the effectiveness of his/her education.

Assets of the project-based method: it is a big motivation drive; it occupies the pupil, shapes his/her personality and encourages cooperation, communication; it allows pupils to discuss their opinions; it makes them look up information and process it afterwards; it develops imagination and creativity; it differentiates pupils in accordance with their inclinations and interests; projects also lead towards internal discipline, tolerance, responsibility and morality of the guide and the guided ones.

Project-based methods, however, also present us with certain difficulties, that must be known to every teacher, who wants to solve them and implement the project-based education. Among the main difficulties are:

- to think the organization and management of given project over - too much benevolence may result in nullification of that project's meaning

- to sensitively estimate the amount of freedom and responsibility to be given to pupils

- to consider elements of organization well

- to consider timetabling

- to evaluate the project's adequacy

\subsection{Categories of Projects}

The organization structure of project-based education can vary a lot. The founder of project based method himself, Mr. Killpatrick, distinguishes projects according to their objective (Valenta, 1993): 
- Projects endeavouring to incorporate an idea or a plan into an outer form. It resembles a construction of reality.

- Projects leading to an aesthetical experience.

- Projects striving to solve a problem.

- Projects leading to acquiring a skill.

From the same point of view, Hosic differentiates projects as follows:

- Problem-based - e.g. why most of railways were built in late $19^{\text {th }}$ century.

- Construction-based - e.g. building a model of a medieval fort

- Evaluation-based - e.g. to study and compare two building companies

- Drill-based - e.g. to retain locomotive faculties

- Projects can also be differentiated according to the mover:

- Spontaneous - they originate in pupils' needs and interests

- Synthetically prepared - they are presented by the teacher, lecturer or educator

- Both - they arise from one subject, but are coordinated by the other

According to the place of event we distinguish:

- School projects - they take place in an educational institution and on appointed time

- Home projects - they take place away from school

- Connection of home and school environment - these types can follow up each other

- Another criterion for differentiation can be the number of pupils:

- Individual

- Collective - group-based, intraclass-based, interclass-based, school-based

- Combined individual and collective projects

According to the time dedicated to the project, we distinguish:

- $\quad$ Short-term projects - they last e.g. for a day or even for one lesson

- $\quad$ Long-term - many days, e.g. even a year

- According to the size (number of tasks, their demands), we distinguish:

- Small projects (e.g. preparation of a meal)

- Big projects (e.g. building a study or workroom)

Regarding concentration, projects can be organized:

- Within one subject - either as a part of another educational system or as the exclusive method of teaching a subject.

- Within related subjects - similar to $1^{\text {st }}$ group.

- $\quad$ Outside the education process - they stand next to subjects; they usually cover various subjects or realms of knowledge.

- Instead of subjects - they can be limited by time.

\subsection{Basic Steps towards Realization of a Project}

While realizing a project we have to comply with four basic steps stated by Killpatrick (Valenta, 1993):

1) Project objectives - first, one has to draw up a project plan, which consists of specific ideas about the meaning, implementation and objectives of the project. We recognize two levels of project objectives:

a) The motivation itself, which plays a specific role with spontaneous projects (coincidence, mood, motivation)

b) Formulation of the project basis (when phrasing the conclusion)

2) Processing the plan - transforming the objectives into separate steps, determining the time required by the project, means to be used, type of activities, assignment of roles and tasks to individuals and groups. 
3) Project implementation - processing by the plan, the teacher stands in background, but can also play the role of a leader, organiser, chief, spokesperson, moderator etc.

4) Project evaluation - both teachers and pupils take part on this, and the evaluation can at the same time become the basis of further projects. During the evaluation the whole event is assessed, other solutions and methods are searched for.

Project-based education allows pupils to cover the whole structure of an activity, from planning and attempts to solve the problem, to achieving the goal. It connects thinking and experiencing, theory and practice, school and life.

\section{Creative Teaching Methodology}

The creative teaching methodology comprises a psychologically justified and pedagogically effective system of methods, forms and strategies of teacher's work to develop creativity in pupils (Loksova \& Loksa, 2001). As learning is the fundamental activity of pupils, the teaching process seems to be the most effective opportunity for developing their creative abilities. The development of these abilities then depends on the curriculum contents and teaching process procedures and objectives. It is important in the psychological point of view that instructions are formulated precisely, training variations considered well, means chosen appropriately, and that purpose and results are clear. The psychological approach, however, is only one of the creative teaching component parts. Another, also important part of creative teaching is the pedagogical aspect. This point of view emphasizes appropriate incorporation of the methods into the entire education system, in particular then into teaching subjects and situations, creation of suitable conditions, thinking out the time scheduling, combinations and variations of the methods, and verification of the benefits of individual methods.

The methodology of creativity development in the teaching process forms a system which should be supplemented continuously. In practice it means to learn not only the theory of creative teaching but also as many methods and techniques as possible for creativity development and, at the same time, be able to apply these techniques and methods systematically, thoughtfully and professionally in teaching. The creative teaching methods concern the various areas of creativity development, develop different abilities, and make use of different means and techniques. There are many views as how to classify the creativity development methods and different authors classify them from different points of view.

\section{Requirements for Training in Creativity in Teaching Profession Students}

In the following we will try to summarize the requirements that should be satisfied in teaching technical or working subjects, for instance, so as to develop creative abilities in teaching profession students:

Do not mediate "ready-made" knowledge of materials, tools, aids and procedures only to students.

Do not prescribe detailed working procedures for students' activities at seminars.

- Lead students more frequently to apply problem situations, heuristic and divergent assignments which require not only active cognitive activities but also generation of new solution procedures, strategies and methods and application of creative thinking abilities.

- Use information and communication technologies in work and preparation.

- Lead students to effective work planning while observing the didactic principles.

- Formulate in students positive relations to humanistic application of technology - approximation of working teaching to the human nature, universal development of pupils' personalities, new relationships between teachers and pupils, establishment of an optimum social climate in classroom, etc.

- Motivate students to active work at seminars and teach students how to motivate pupils properly.

- Create a comfortable working environment for students to work creatively.

- Prepare students so as to be flexible and adaptable sufficiently to the rapidly changing conditions in technology development.

The above requirements are, of course, also applicable to primary schools where creative teaching is appreciated as learning through activities, based on the following principles:

$>$ Learn - search for new information;

$>$ Evaluate - distinguish information relevancy, incorporate information into systems;

$>$ Experience - choose decisions in new situations; 
$>$ Communicate - exchange and evaluate information;

$>$ Practical doing - realize projects, apply knowledge.

\section{Results of the Research of Creative Abilities in Primary Czech School Pupils}

In compliance with the research goal, we raised the fundamental questions of the research:

I. Is there any connection between the results reached in Torrance Figural Test of Creative Thinking and the results reached in the Test of technical imagination - Construction and shape test?

II. Has the respondents' age factor any influence on the final score of the Torrance tests?

III. Has the respondents' age factor any influence on the final score of technical imagination?

IV. Is there any significant difference in reaching both tests results with the students of $1^{\text {st }}$ stage and $2^{\text {nd }}$ stage of elementary schools?

V. Are there any significant differences in the results reached in both tests within the academic groups?

\subsection{Research Realisation Timetable}

Field research study started in February 2007 and finished in March 2008. During this period, the research workers were testing the respondents by creativity tests. They also monitored the research progress and reported research data that were consequently evaluated and statistically processed.

\subsection{Research Methods}

When gathering data, we used standardized tests of creativity:

- Construction and shape test for identification of technical imagination level.

- Torrance figural test of creative thinking for identification of creative thinking level.

- Statistic methods for verification of defined hypotheses.

- Monitoring of research work.

\subsection{Elementary Schools Research Results}

Research results were evaluated, statistically processed and they are presented here in the form of curves of development.

Approximately five hundred respondents - pupils of primary schools - took part in the research. The research results were evaluated, processed statistically, and presented here as development curves. Graph No. 1 shows the development of technical creativity (imagination) examined using the Pattern Assembly Test. Graph No. 2 shows the development of creative thinking examined using the Torrance Figural Test of Creative Thinking.

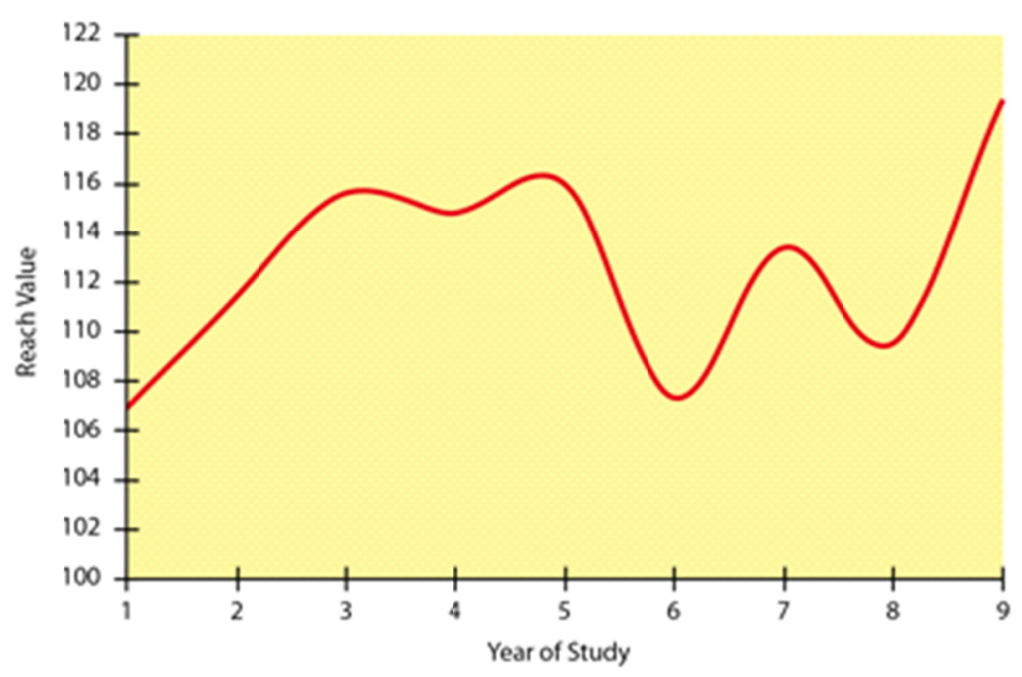

Graph 1. Construction and shape test curve of development 


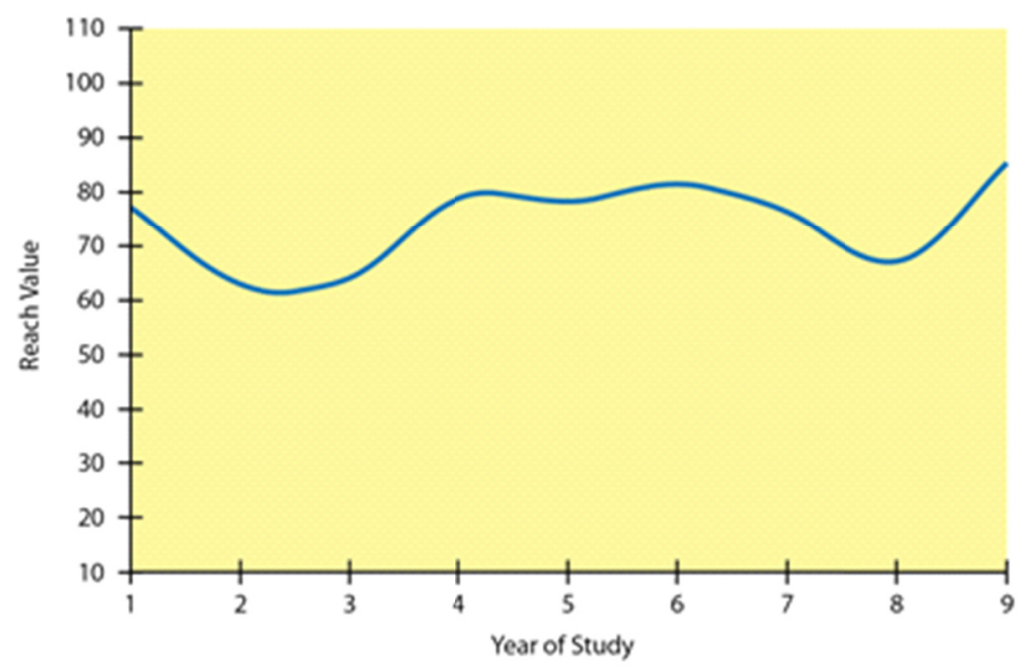

Graph 2. Torrance tests curve of development

Comparison of the creative thinking development and technical creativity (imagination) development is showed in the Graph No. 3.

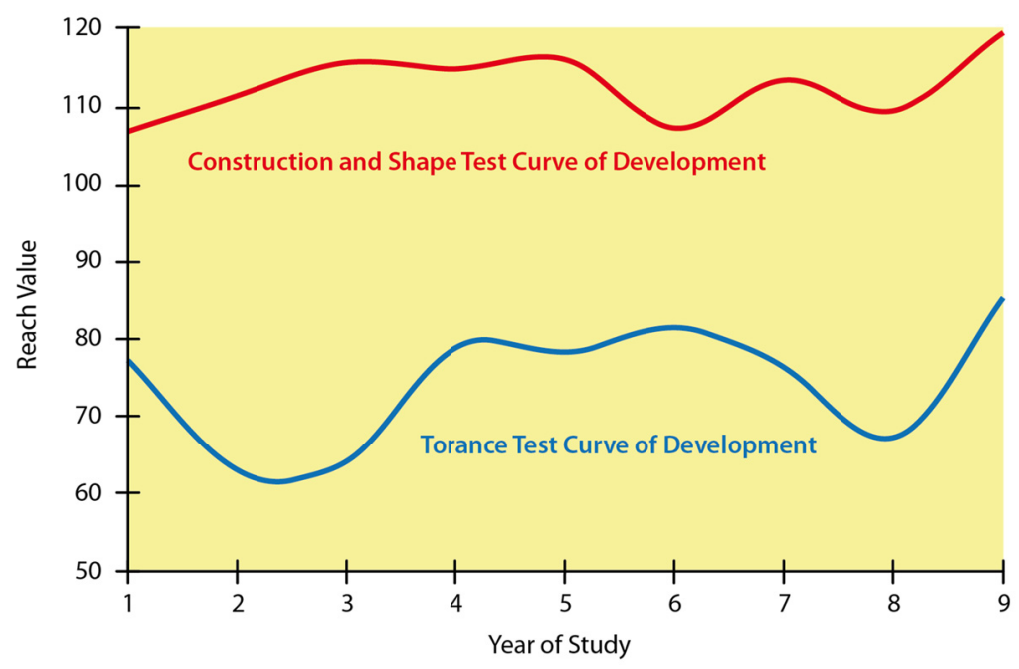

Graph 3. Curves of development - comparison

The research results have indicated the respondents (or the age group) that require being assigned more with tasks of a constructive character, i.e. those for technical creativity (imagination), and when to focus more on creative thinking, i.e. include teaching projects with problem elements which lead pupils to independent creative thinking.

\subsection{Results of the Research of Creative Abilities in All Respondents}

Teacher's personality takes a great part in creative ability development. The following curves show the development of creative abilities in respective age groups - pupils of the $1^{\text {st }}$ and $2^{\text {nd }}$ grades of primary schools, students of the Faculty of Education, and practicing teachers. Graph No. 4 shows the development of technical creativity examined using the Pattern Assembly Test; Graph No. 5 shows the development of creative thinking examined using the Torrance Figural Test of Creative Thinking. 


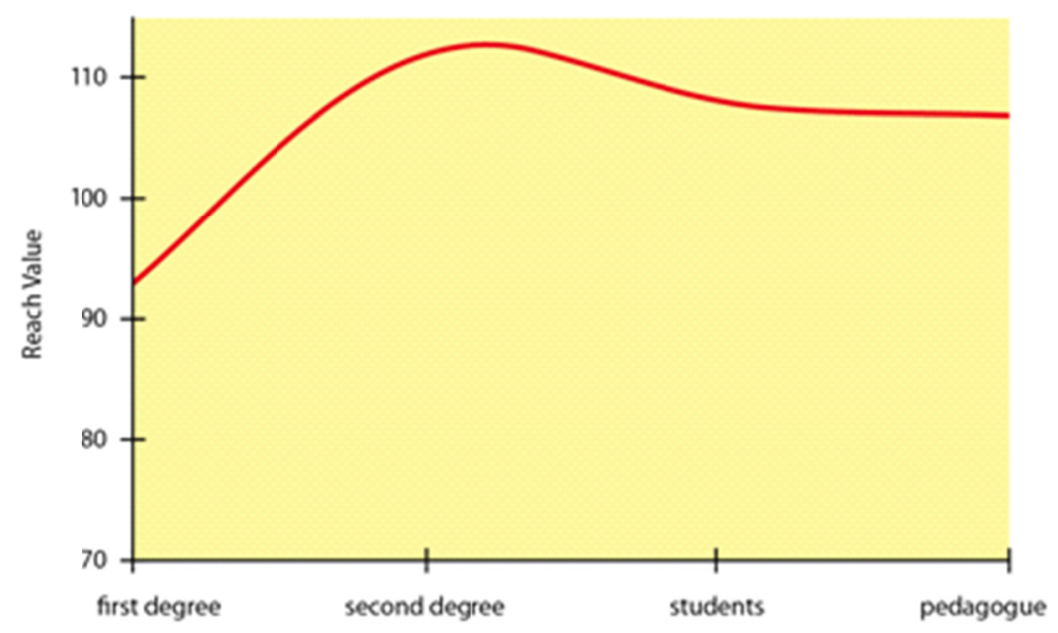

Graph 4. Pattern assembly test

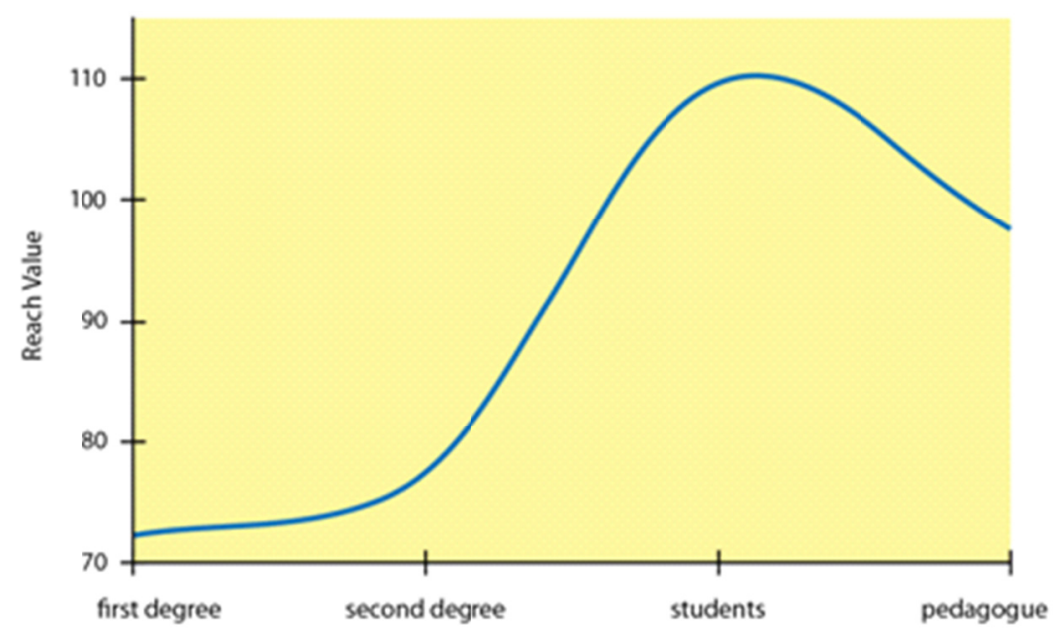

Graph 5. Torrance figural test of creative thinking

The Graph No. 6 shows the comparison of technical creativity and creative thinking in the individual groups.

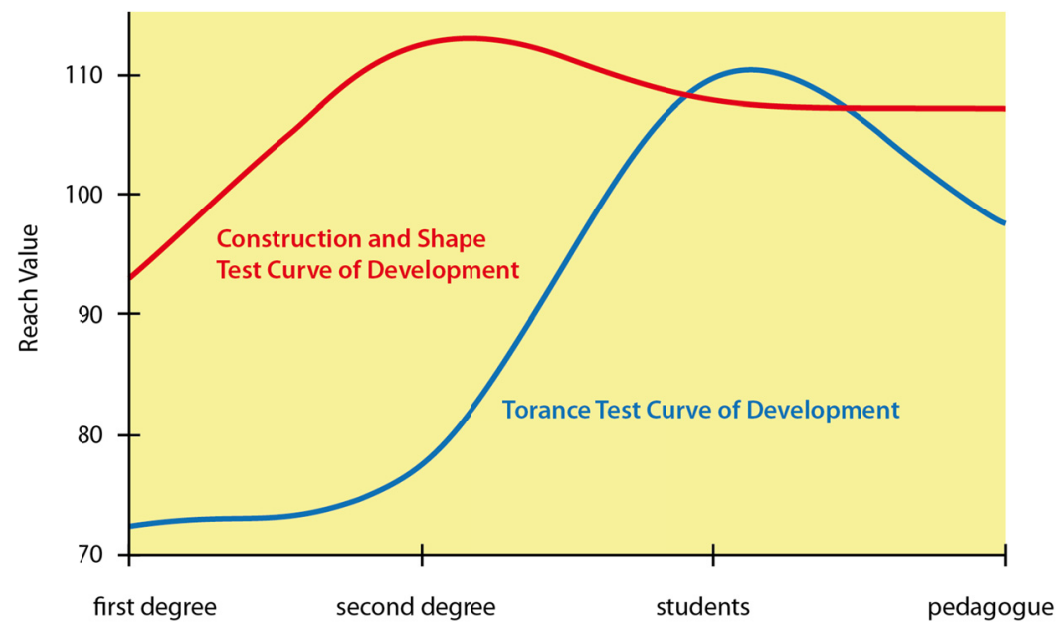

Graph 6. Comparison of technical creativity and creative thinking in the individual groups 
The last Graph No. 7 shows measured mean value off of all groups.

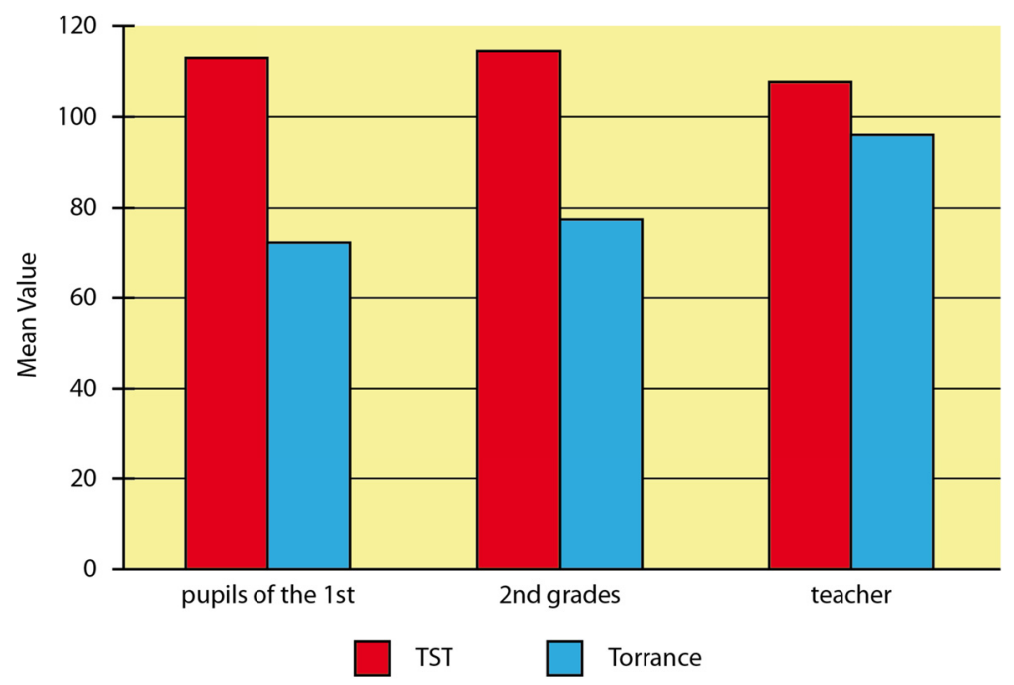

Graph 7. Mean value off of all groups

\section{Study Programmes Innovation, Change of the Management and Work Style at Elementary Schools}

Research, concerning the students and teachers creative skills level at elementary schools and faculties of education, mapped how creative our young generation is. In order to reach the high level of creative skills within whole population, it is necessary to start with the youngest. We need to change the style of work at our elementary schools, open the schools for the outside world, lead our children to independent thinking, and develop their technical thinking from the very beginning of their lives. This is the only way how the technical disciplines can present the specialists of high quality in the future.

Main goal of the project under the name Nonverbal creativity in technical education was to create an educational programme for creative teaching of technical education at our elementary schools - Creative technical work. There was an optional subject integrated to pedagogic study programmes under similar name. The research also shows that the teaching goals like creativity and adaptation are nowadays specified by teachers as very important in education programmes, but the practice is usually very different. If the activities in the education field Man and the world of work should develop creative thinking and imagination, they need to be worked out mainly as problem-solving tasks and teaching projects. All-school teaching projects are usually very effective.

Tasks for creative skills development include the programme called Creative technical work, labelled as CTW (in Czech language TTP- Tvorive technicke prace).

C- Creative thinking - new ideas in working with different materials, active participation, independence, terminology, utilisation of crafted products;

T - Technical imagination - constructive tasks, assembly and dismantling work;

$\mathbf{P}$ - Projects and problems - their realisation in technical education, interconnection of gained knowledge and skills within the project realisation, problem solving.

\section{Teacher's Contribution to Creativity Development}

The project also results in recommendations to teachers as to how release creative abilities in children. But teacher should not only use different methods in creativity development but also foster such qualities in children that are required for adaptation in new conditions or situations and that are mostly formed of divergent thinking. And how should teachers foster qualities so necessary for creative ability development in their pupils? Pupils' creativity development in the education process requires that teachers apply the following approaches as formulated in a well-arranged manner by Loksova, Loksa (Loksova \& Loksa, 2001), in their classes:

- Motivate pupils so that they are pleased and happy to have understood the taught matter;

- Develop knowledge in pupils within meaningful structures; 
- Support the development of independence, self-reflection and responsibility in pupils;

- Support the development of self-assurance and self-confidence in pupils;

- Support willingness in pupils to risk in solving tasks;

- Support the development of individual talents in pupils;

- Encourage pupils to produce ideas, inspiration, and ask questions;

- Generate a creative climate in classrooms where humour and laughter apply and the teacher is a helper as well as a superior to pupils.

In essence, when implementing the theoretical conception of creative teaching in school's practice, it is possible to follow from transforming retroactive education to proactive, while the term retroactive education is understood to be such education approach in which the teacher defines a particular activity for pupils aiming to make children busy in an unspecified manner. Thus focused education is deemed to be rather against creativity development. Proactive education, on the other hand, represents the contrary of the previous education approach - the teacher never tires of inventing new games and assignments, and chooses such methods and procedures so as to continuously develop the pupils optimally in compliance with the education objectives. If the education of an individual should develop his/her creative abilities, he/she must be continuously put into new situations unknown to him/her before (Loksova \& Loksa, 2001).

\section{Conclusion}

The mentioned research survey showed that our educational public shows a somewhat satisfactory level of creative ability, applying different methods and forms of work. The teaching creativity, however, mainly reflects on creative work with the educational content and less on aims and also forms and methods of work.

The fact that project and problem methods of teaching are at least partially returning to our primary schools can be evaluated very positively. Such methods enable the pupils' self-realization, they provide an opportunity to assert one's own opinions, to be able to organize one's work, to learn how to work as a team. These methods also allow the connection of theory and practice, thought and experience, which some other methods cannot do. Problem and project methods can therefore be consider the as very important in terms of creative teaching, whose main task is to trigger creativity in pupils. Every lesson should provide pupils with enough space for creative work. Several conditions could be determined for such a lesson - providing opportunities for the pupils' creative work, their support, appraisal of their ideas and thoughts, providing enough time to think about the problems, to construct ideas and to develop imagination. This is also true in the application of project and problem teaching, which can be excellent methods of developing creative abilities of pupils. It is therefore clear that project and problem methods should find a permanent place in primary schools. However, these methods also have their drawbacks as they require much more time to prepare, some experience, and technical and information facilities of the school. It is a very difficult and challenging process especially for the teachers' ability, may it be organizational skills, managerial skills, and the ability to anticipate and respond flexibly to arisen situations, their knowledge, pedagogical and psychological abilities. Compared to a conventional style of teaching, project and problem methods also bring an increased mobility of pupils within school education and thereby increase the demand for the perfect organization of the class unit. A good teacher must overcome these challenges and find their own path that will bring them and their pupils not only more success and joy in the classroom, but also more knowledge and experience.

\section{References}

Badegruber, B. (1997). Otevrene uceni v 28 blocich. Praha: Portal.

Bajtos, J. (2003). Teoria a prax didaktiky. Zilina: Zilinska univerzita v Ziline.

Bezjak, J. (2009). Project learning of model PUD-BJ - from idea to the product. Klagenfurt: LVM for Verlag S. Novak.

Cap, J., \& Mares, J. (2001). Psychologie pro ucitele. Praha: Portal.

Chraska, M. (2007). Metody pedagogickeho vyzkumu. Praha: Grada.

Greca, I., \& Marco, A. (2000). Mental models, conceptual models, and modelling. International Journal of Science Education, 22(1), 1-11. http://dx.doi.org/10.1080/095006900289976

Hlavsa, J. (1981). Psychologicke problemy vychovy k tvorivosti. Praha: SPN.

Honzikova, J. (2001). Pracovni cinnosti na 1. stupni ZS. Plzeň: ZCU. 
Honzikova, J. (2004). Projektova metoda a jeji aplikace. Technologia vzdelavania: vedecko-pedagogicky casopis., 12(1), 5-8.

Honzikova, J., \& Novotny, J. (2006). Projektove a problemove metody v praxi. E-PEDAGOGIUM., 4(2), 28-40.

Janovec, J., \& Hermanova, V. (2011). Rozvijeni kompetenci ucitelu primarniho vzdelavani v oblasti Clovek a svet prace se zamerenim na psychomotoricke dovednosti zaku. In Technologie vzdelavania v priprave ucitelov prirodovednych a technickych predmetov (pp. 156-160). Presov: Presovska univerzita v Presove.

Kerlinger, F. (1973). Zaklady vyzkumu chovani. Praha: Academia.

Loksova, I., \& Loksa, J. (2001). Teoria a prax tvoriveho vyucovania. Presov: ManaCon.

Manak, J. (1998). Rozvoj aktivity, samostatnosti a tvorivosti zaku. Brno: MU.

Miklosikova, M. (2009). Kreativita and teaching special articles. Ostrava: VSB.

Petrova, A. (1999). Tvorivost v teorii a praxi. Pribram: Vodnar.

Spickova, K. (2007). Pracovni cinnosti na 1. stupni zs a jejich vyuziti pro rozvoj psychomotorickych dovednosti. (Unpublished master's thesis).

Svec, V. (1997). Sebereflexe v pedagogicke cinnosti ucitele. Brno: PF MU.

Valenta, J., \& Kasikova, H. (1993). Pohledy-projektova metoda ve skole a za skolou. Praha: Arama. 